\title{
Late life suicide in Italy, 1980-2015
}

\author{
Diego De Leo ${ }^{1,2} \circledast$ Monica Vichi ${ }^{3} \cdot$ Kairi Kolves ${ }^{1} \cdot$ Maurizio Pompili $^{4}$
}

Received: 25 September 2019 / Accepted: 21 November 2019

(c) Springer Nature Switzerland AG 2019

\begin{abstract}
Aim Suicide trends in older adults were examined in Italy from 1980 to 2015. Age groups considered were 65-74 years, $75-84$ and $85+$ years.

Methods Data on suicide deaths were obtained from the Italian Mortality Database (IMDB) collected by the Italian National Institute of Statistics (ISTAT) and processed by the Statistics Unit of the Italian National Institute of Health (Istituto Superiore di Sanità). Joinpoint regression analyses were carried out for age subgroups by sex. In addition, data related to four main macro-areas of Italy were considered: North-West, North-East, Centre, and South with Islands (Sicily and Sardinia). Results Starting by 1985, declines were noted in all age groups with more noticeable decreases in older adults aged 75-84 and $85+$ years. Female subjects demonstrated more ample falls in rates than male individuals. Declines were detected in all macro-areas of Italy.

Conclusion Improved health assistance and quality of life of older individuals have probably contributed to the decline of suicide rates of senior citizens, who also showed improved poverty indices in the country, differently from all other age groups.
\end{abstract}

Keywords Old age $\cdot$ Suicide rates $\cdot$ Italy $\cdot$ Macro-areas $\cdot$ Sex differences $\cdot$ Poverty indices $\cdot$ Threshold for seniority

\section{Introduction}

Based on data from the Global Burden of Disease Study, in 2016 there were 817,000 deaths due to suicide in the world [1]. Between 1990 and 2016, suicide absolute figures have increased by $6.7 \%$; however, age-standardised mortality rates have globally decreased by $32.7 \%$ : from $16.6 / 100,000$ in 1990 to $11.2 / 100,000$ in 2016 [1]. The same study indicated that, despite the general decline in rates of suicides in the world, for individuals aged 70 years and over suicide rates have remained the highest across all regions of the globe. Moreover, as already indicated by the World Health Organization's (WHO) report, Preventing Suicide: The

Diego De Leo

d.deleo@griffith.edu.au

1 Australian Institute for Suicide Research and Prevention, Griffith University, Mt Gravatt Campus, Brisbane 4122, Australia

2 Slovenian Centre for Suicide Research, Primorska University, Koper, Slovenia

3 Istituto Superiore di Sanita', Rome, Italy

4 Psychiatric Clinic, University of Rome 'La Sapienza', Rome, Italy
Global Imperative, in the past decades, suicide rates among older adults have been decreasing more than in any other age groups. The reasons for this trend were not fully understood; however, the decline in suicide rates was not attributed to any specific campaign aiming at the prevention of suicide in old age, but was rather highlighting the improvements in health care and in quality of life witnessed by the general population, with the most fragile demographic segment of it, older adults, particularly benefitting from these improvements [2]. In addition, according to the Organisation for Economic Co-operation and Development (OECD), in many countries, indices of poverty among older individuals ( $65+$ years of age) have improved more than in other age groups, especially in the age band 66-75 (OECD, 2018).

Poverty and low socio-economic status have been reported as risk factors for suicide in late life in many nations worldwide $[3,4]$. For example, the high suicide rate witnessed at the end of the century among older people in rural China (i.e. 109/100,000 in males over the age of 75) was possibly related to the experience of serious hardships in everyday living, limited access to health care facilities (along with lack of pension programmes), and very limited government support [5]. Since then, the country has witnessed rapid economic growth, improved standards of 
living, massive urbanisation, and improved access to medical assistance, especially in rural areas [6]. These progresses are possibly at the basis of the large decrease in suicide rates occurred in China between 1990 and 2016, which was in the amount of $64.1 \%$, the biggest decline recorded in the Global Burden of Disease Study during the same timeframe [1].

\section{'Limits' of old age and suicide data limits}

There are no internationally operating agreements on the demographic boundaries for belonging to the 'older adults' category. The choice of 65 years of age as the threshold to enter old age-wrongly attributed to Otto von Bismarck [7]—is usually, although inconsistently, chosen as age boundary. Frequently, older adults have been grouped into the categories of the 'young old' (65-74 years of age), 'old' (75-84 years) and 'oldest old' (85+ years) [8]. However, improved conditions in general health of individuals and subsequent increased longevity have rendered quite questionable large aggregations of people under the unifying label of 'older adults', given the marked differences existing today among the above-mentioned subgroups of people. Especially in high-income countries, people aged 65-74 years are usually in good health and continue to benefit-as in younger ages-from satisfactory levels of social inclusion and availability of resources. People aged $75+$ years instead frequently start showing some evident signs of physical decay or impairment and some degree of dependency on others. Following this line of reasoning, for example, on 29 November 2018, the Italian Society of Gerontology and Geriatrics (ISGG) has formally endorsed the limit of 75 years of age as the beginning of 'old age' [9]. Raising the threshold for seniority from 65 to 75 years appears, in fact, as better suited to the current physical and mental performances of men and women living in highincome countries and to the demographic situation of the Italian population, one with the highest longevity indices in the world. This modification (the implications of which are much ampler that the mere demographic dimension) was proposed and approved on the occasion of the 63rd National Congress of ISGG held in Rome at the end of November 2018 [9].

It is perhaps difficult to think that the way in which the 'elderly' are classified and perceived in a given society does not have repercussions also on risk factors for suicide. Hypothetically, moving ahead the formal entry into 'old age' could have consequences-among the others-also at the psychosocial level, by creating the expectation of a better sense of acceptance and belonging for a demographic group of people still considered to be functionally active, dynamic and resourceful. Clearly, only the future would confirm this hypothesis (and hope). However, it might be hypothesised that not everyone would benefit equally from this move.
For example, manual labour jobs can lead to more physical health problems, in particular at younger ages and certainly before the age of 75 years. Also those with lower incomes and financial resources - both earlier in life and in late lifecould be forced to work beyond when they feel they would like to or feel they can, especially if government programmes that provide income were to be allocated 10 years later, as is possibly an implication of the Italian Society of Gerontology and Geriatrics proposal noted. In addition, those with lower incomes may neglect or delay health issues due to costs involved (and have possible dietary differences, live in housing conditions that are less healthy, etc.), which also affect health, both physical and mental, as one reaches late life ages. In any case, improvements for many elders have certainly taken place, and it is indeed reasonable to suggest them as possible explanations or contributors to the generally lower suicide rate trends in late life.

Despite these considerations, what is being observed is that suicide rates continue to be the highest in late life, particularly among males. For example, a study conducted by Shah and associates [10] showed that suicide rates continue to increase in centenarians too. A remarkable phenomenon is represented by the progressive widening of the disproportion between suicide rates of males and those of females, with males of very advanced age expressing rates of suicide up to 7-8 times bigger than those of old-old females [10] (in younger age groups of western countries the suicide rate ratio between males and females is approximately three to one). This phenomenon has not been fully clarified, but it seems to imply the aggregation of several different risk factors for older males, and/or the increase in their severity with the ageing process $[11,12]$.

A note of caution should be expressed in relation to the validity of data on suicidal mortality in general and for those concerning old age in particular $[13,14]$. In fact, mortality data for suicide in older adults are often underestimated. Deaths resulting from suicide are often not examined, but reported as accidents or deaths due to natural causes, just because the deceased was an elder [15]. Refusal to take life supporting drugs or overdosing on medications such as insulin or opioids resulting in death can easily be recorded as accidental and not due to suicide [16]. In Australia, Walter and associates [17] found a significantly lower number of death investigations in cases involving older adults compared to younger age groups, either due to suicide or every other cause. Conversely, deaths involving children or resulting from medical complications and road accidents attracted most investigations [17].

\section{Scope of the study}

This investigation aimed at examining trends of suicide in older adults of Italy for the years 1980-2015 (latest available 
complete data set). This timeframe appeared to be sufficiently long to provide reliable observations of the evolution of the phenomenon. From a socio-economic perspective, Italy's general population witnessed own developmental zenith along the 80s [18]. Since then, a slow declining phase started, which still continues today, making of Italy the country with the lowest growth indices of Europe (OECD, 2018). Big disparities exist between the rich north and the poor south of the country, with the north-eastern part of Italy considered being the richest area of the entire country [19]. Whilst the country has progressively impoverished, especially in the most productive fringes of its population (young adults and adults), almost unexpectedly in older adults poverty indices have marked positive variations (OECD, 2018). We, therefore, aimed to consider possible variations also in suicide rates of the old age segment of the population, traditionally at higher rates than any other age group [20]. In this study we also examined suicide deaths' distribution within the country by geographical subdivisions.

\section{Materials and methods}

\section{Data}

In 2015, Italy was a country of about 60 million inhabitants, the 15-64 years old representing approximately $64 \%$ of the general population, the youngest age group (0-14) $14 \%$, and older adults (65 years and over) 22\% (about 13 million inhabitants). The country is divided into 21 administrative regions that are grouped in four geographical macro-areas: North-West [NW], North-East [NE], Centre [C] and SouthIslands [SI].

Data on suicide deaths in 1980-2015 were obtained from the Italian Mortality Database (IMDB) collected by the Italian National Institute of Statistics (ISTAT) and processed by the Statistics Unit of the Italian National Institute of Health (Istituto Superiore di Sanità). The IMDB includes all death certificates' information of Italian residents who died in Italy; ISTAT codes the underlying cause of death according to the International Classification of Diseases (ICD). Suicide deaths are coded under "External Causes": E950-E959 (ICD-9 rev) for the year 1980 to 2002, and X60-X84, Y87.0 (ICD-10 rev) for the years from 2003 to 2015 (latest available when the present study was carried out). Given the fact that we analysed official data made available by the Italian National Institute of Statistics, ethics committee approval was not sought after.

\section{Statistics analysis}

Age-adjusted annual mortality rates for suicide per 100,000 inhabitants were calculated using the Standard European
Population as a reference (https://ec.europa.eu/eurostat/ documents/3859598/5926869/KS-RA-13-028-EN.PDF/ e713fa79-1add-44e8-b23d-5e8fa09b3f8f).

Analyses were performed separately for men and women. Age-specific rates were computed for all age groups. Temporal trends were analysed for population aged 15-64 years and 65 years and over (the focus of this study was on older adults. Comparison with more discrete age groups of younger population would be the focus of future investigations). In this study, for older adults, separate analyses were conducted for the following age groups: 65-74 years, $75-84$ years and 85 years and over.

Trends were analysed for the 36-year period, from 1980 to 2015 , using joinpoint regression analysis. Estimated Annual Percentage Change (APC) with 95\% confidence intervals (CIs) was computed for each detected trend. A maximum of 3 joinpoints were allowed, and the "minimum number between two joinpoints" and "between a joinpoint and the end of data" was set to 5. In the final model, each joinpoint (if any were detected) indicates a significant change in the slope. Joinpoint analysis was applied to the age-adjusted rates (and their standard errors) for the age class 15-64 years and 65 years and over. For the age groups $65-74,75-84$ and 85 years and over, joinpoint regression analysis was applied to the crude age-specific rates. Models were estimated separately by sex, age groups and geographical regions. APC was considered (statistically) significantly different from zero if 95\% CI did not include zero. Where appropriate, the average of estimated APC (AAPC) was calculated. The AAPC is a summary measure computed over a fixed interval as a weighted average of the slope coefficients of the joinpoint regression, with the weights equal to the length of each detected segment over the interval (if there are no joinpoints during the selected period, AAPC corresponds with the APC).

Analyses were performed in IBM-SPSS 25 (IBM-SPSS Corp., Armonk, NY USA) and SAS 9.4 (SAS Institute, Cary, NC USA). Rates were computed with an integrated system of programs, PATED (procedure for the spatial analysis of descriptive epidemiology, version 4.3) [21]. Joinpoint regressions were performed by Joinpoint Regression Program, Version 4.7.0.0. by Statistical Research and Applications Branch, National Cancer Institute (https://surveillan ce.cancer.gov/joinpoint/).

\section{Results}

Inspection of Figs. 1 and 2 clearly points to a marked decline in rates of suicide deaths-during the years 1980-2015 in both sexes. From mid-80s, rates of older adults have been halving for both men and women. Nevertheless, the rates seemed to have plateaued since mid-2000s (Fig. 1). 


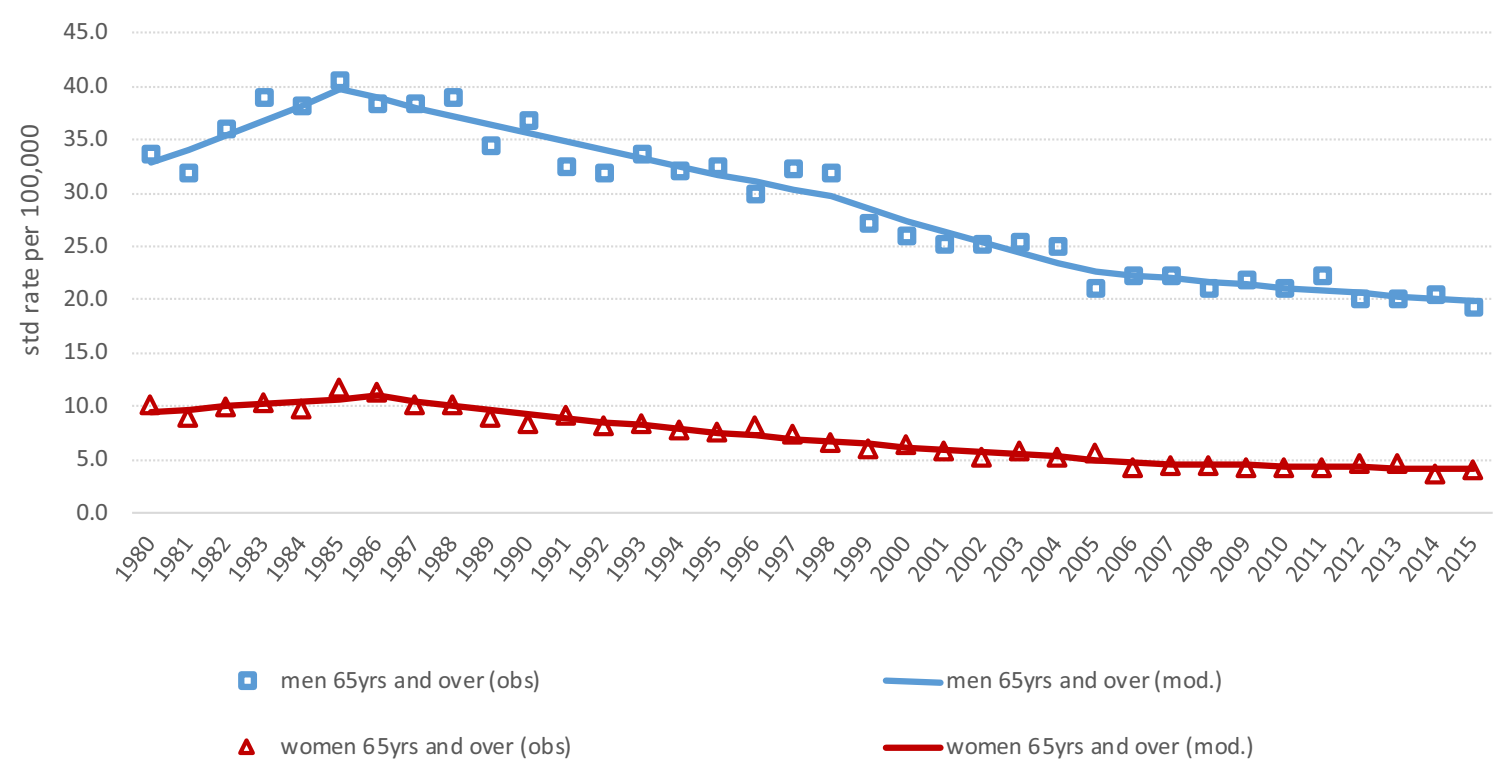

Fig. 1 Age-adjusted suicide rates (symbols) and estimated trends (straight lines). Men and women aged 65 years and over, Italy, 1980-2015

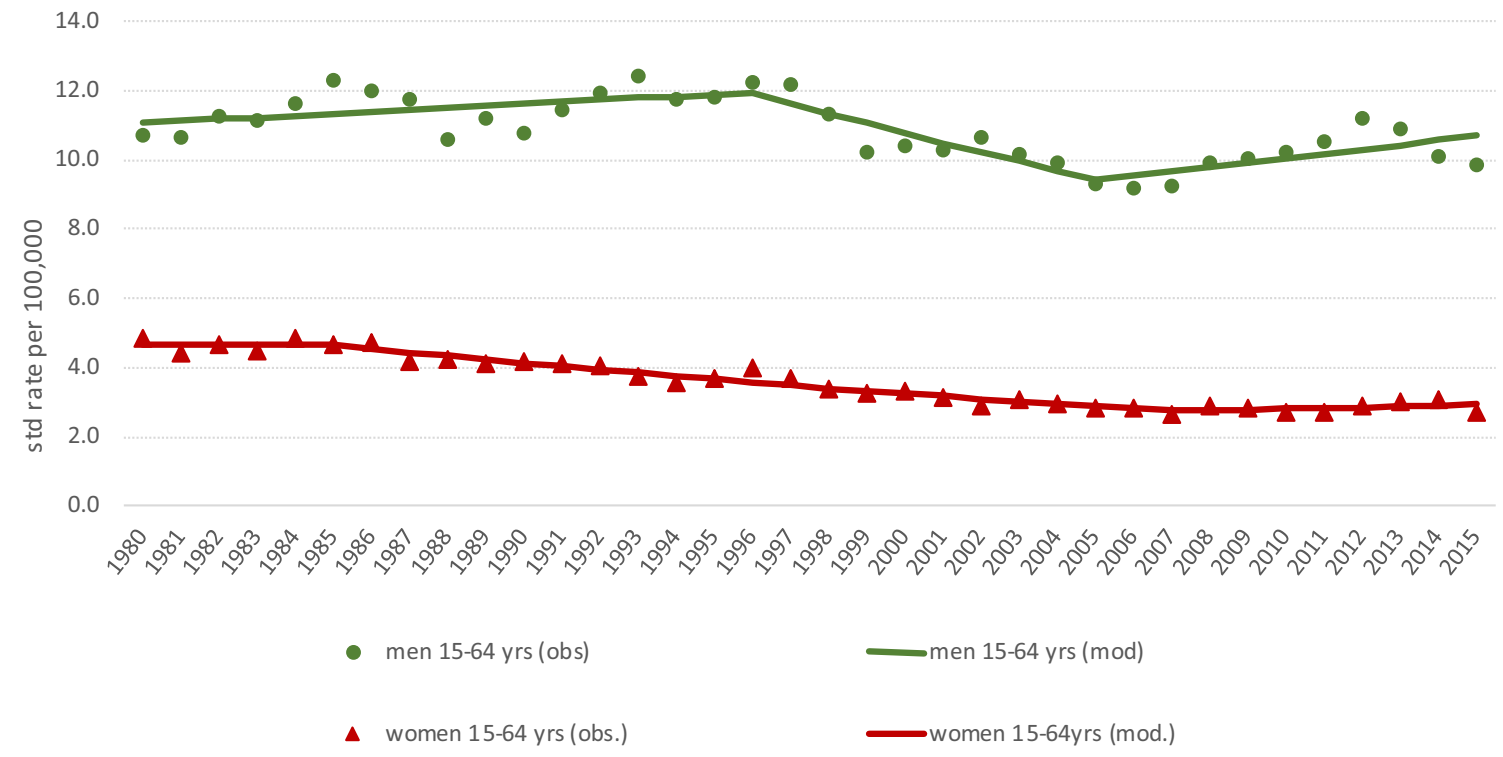

Fig. 2 Age-adjusted suicide rates (symbols) and estimated trends (straight lines). Men and women aged 15-64 years, Italy, 1980-2015

Suicide trends of older adults differ notably from trends of individuals of younger ages (15-64 years) (Fig. 2). Whilst women of the latter age group have decreasing rates since 1980, the decline is less pronounced than that of older women and shows some level of steadiness around midway the first decade of the new Millennium. Men, on the contrary, seem to fluctuate throughout the study period with the rates of the first and last year being on the same level. (Fig. 2).

Joinpoint regression analyses (Table 1) showed four segments in the rates of older men (all significant at $p<0.01$ ), with the first segment showing a significant increase between 1980 and 1985, and the other three segments indicating significant declines, with the most marked happening between 1998 and 2005. Three segments were identified in older women, with the segment 1986-2007 being the only one reaching statistical significance (Table 1).

Three segments were also identified in subjects aged 15-64 years (both sexes). Whilst for men there was a significant decrease between 1996 and 2005, there was also a significant increase between 2005 and 2015 (Table 1). In 
Table 1 Age-adjusted suicide rates

\begin{tabular}{|c|c|c|c|c|c|c|c|c|}
\hline Cohort & Segment & Lower endpoint & Upper endpoint & APC & Lower CI & Upper CI & Test statistic $(t)$ & Prob $>|t|$ \\
\hline \multirow[t]{4}{*}{ Men-65 years and over } & 1 & 1980 & 1985 & $3.9^{*}$ & 1.1 & 6.9 & 2.8 & $<0.01$ \\
\hline & 2 & 1985 & 1998 & $-2.2 *$ & -2.9 & -1.6 & -7.0 & $<0.01$ \\
\hline & 3 & 1998 & 2005 & $-3.8^{*}$ & -5.6 & -2.1 & -4.4 & $<0.01$ \\
\hline & 4 & 2005 & 2015 & $-1.3^{*}$ & -2.1 & -0.5 & -3.3 & $<0.01$ \\
\hline \multirow[t]{3}{*}{ Women -65 years and over } & 1 & 1980 & 1986 & 2.4 & -0.8 & 5.7 & 1.5 & 0.10 \\
\hline & 2 & 1986 & 2007 & $-4.0^{*}$ & -4.5 & -3.5 & -15.3 & $<0.01$ \\
\hline & 3 & 2007 & 2015 & -1.5 & -3.9 & 1 & -1.3 & 0.20 \\
\hline \multirow[t]{3}{*}{ Men-15-64 years } & 1 & 1980 & 1996 & 0.5 & -0.1 & 1 & 1.8 & 0.10 \\
\hline & 2 & 1996 & 2005 & $-2.6^{*}$ & -4.1 & -1.1 & -3.5 & $<0.01$ \\
\hline & 3 & 2005 & 2015 & $1.2^{*}$ & 0.1 & 2.4 & 2.2 & $<0.01$ \\
\hline \multirow[t]{3}{*}{ Women-15-64 years } & 1 & 1980 & 1985 & 0.0 & -2.5 & 2.6 & 0.0 & 1.00 \\
\hline & 2 & 1985 & 2007 & $-2.4^{*}$ & -2.7 & -2.1 & -15.0 & $<0.01$ \\
\hline & 3 & 2007 & 2015 & 0.8 & -0.7 & 2.4 & 1.1 & 0.30 \\
\hline
\end{tabular}

Annual Percentage Changes (ACP) and corresponding 95\% confidence Intervals (95\% CI), ' $t$ ' test and probability levels. Men and women aged 15-64 years and 65 years and over. Italy, 1980-2015

The AAPC $1985-1998$ for men aged 65 years and over is $-2.9(95 \% \mathrm{CI}-3.5,-2.1 ; p<0.01)$

women aged 15-64 years there was a significant decrease between 1985 and 2007 (Table 1).

By subdividing older adults into three subgroups, young olds (destined to no longer belong to the category of 'the elderly' in Italy, as noted before), the olds and the old-olds, some noticeable differences become apparent. The old-olds males presented - as expected - the highest rates (Fig. 3), followed by the group of 75-84 years of age and then by the youngest subgroup. The two oldest subgroups showed more pronounced decline than the younger ones.
As for females (Fig. 4), the profiles of the curves appeared somewhat different from those of the males. First of all, differences in suicide rates between three age groups were less pronounced with the three trend lines virtually merging into one.

Joinpoint analysis identified three segments for men in the age band 65-74, with a significant decline detected between 1985 and 2006 (Table 2). Two segments were shown for the subgroups 75-84 and 85+, with significant declines in more recent years. Similar trends were identified for women, with

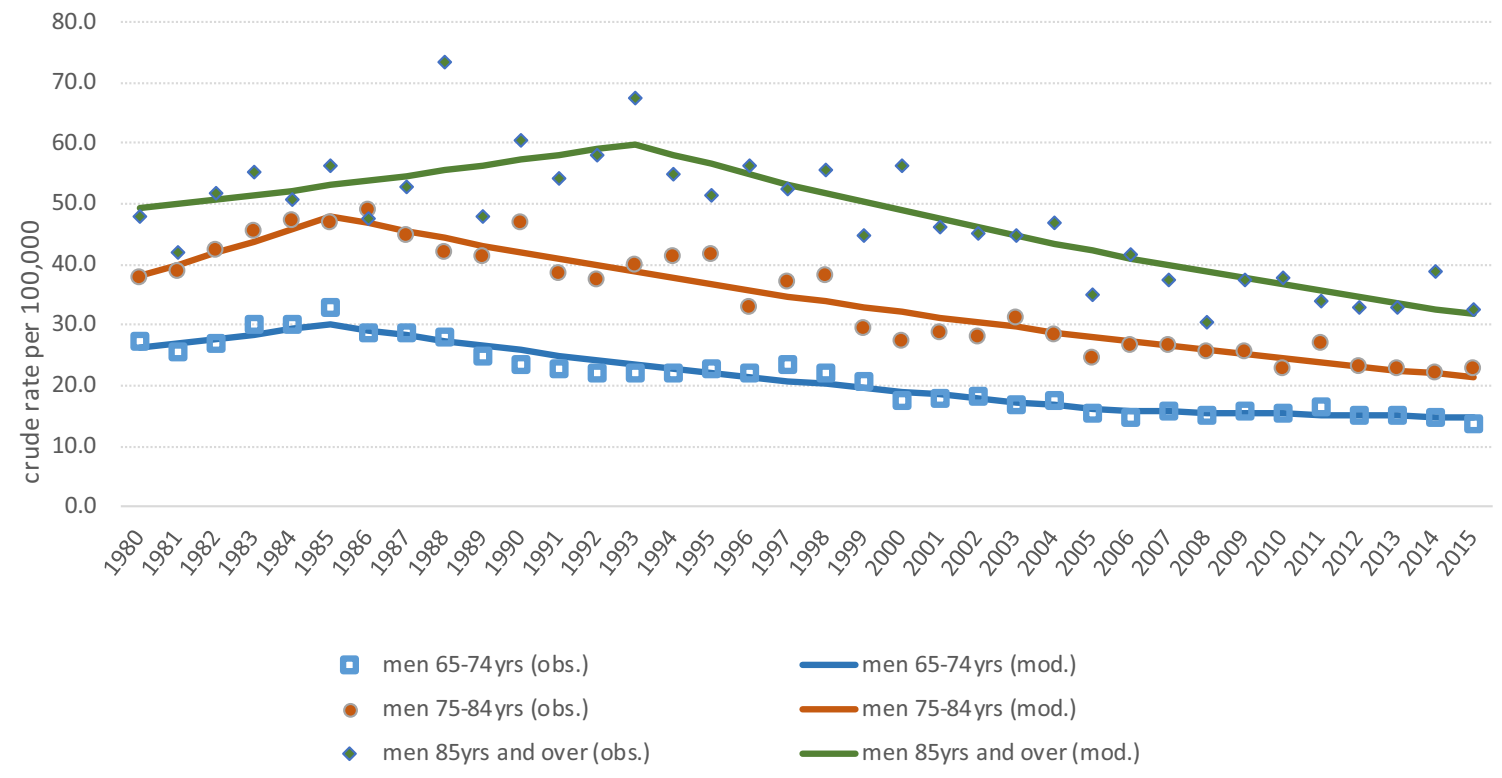

Fig. 3 Crude suicide rates (symbols) and estimated trends (straight lines). Men aged 65-74 years, 75-84 years and 85 years and over. Italy, 1980-2015 


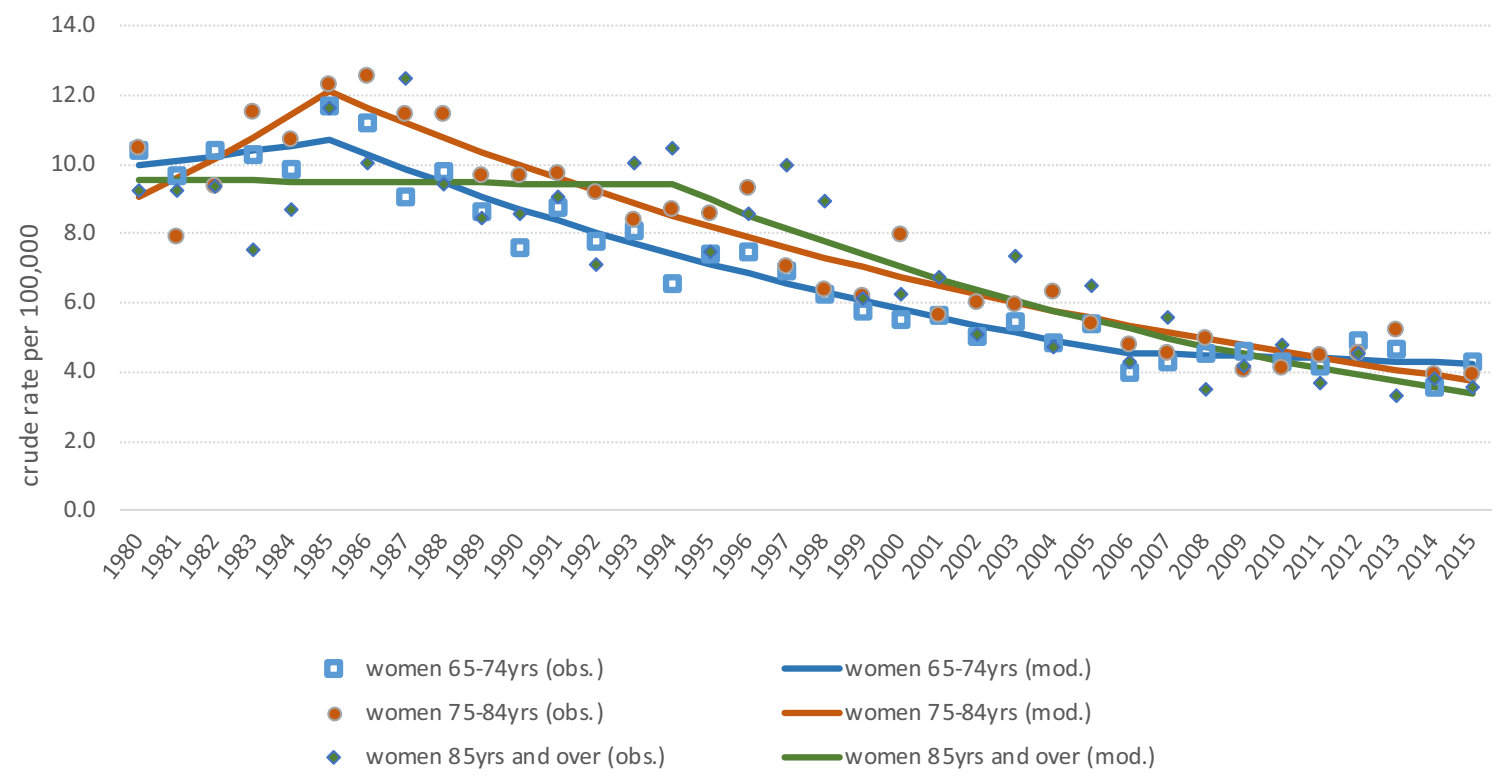

Fig. 4 Crude suicide rates (symbols) and estimated trends (straight lines). Women aged 65-74 years, 75-84 years and 85 years and over. Italy, 1980-2015

Table 2 Crude suicide rates

\begin{tabular}{|c|c|c|c|c|c|c|c|c|}
\hline Cohort & Segment & Lower endpoint & Upper endpoint & APC & Lower CI & Upper CI & Test statistic $(t)$ & Prob $>|t|$ \\
\hline \multirow[t]{3}{*}{ Men 65-74 years } & 1 & 1980 & 1985 & 2.6 & -1.0 & 6.3 & 1.5 & 0.10 \\
\hline & 2 & 1985 & 2006 & $-3.0 *$ & -3.5 & -2.6 & -13.5 & $<0.01$ \\
\hline & 3 & 2006 & 2015 & -0.8 & -2.4 & 0.9 & -0.9 & 0.40 \\
\hline \multirow[t]{2}{*}{ Men $75-84$ years } & 1 & 1980 & 1985 & 4.8 & -0.5 & 10.4 & 1.8 & 0.10 \\
\hline & 2 & 1985 & 2015 & $-2.7 *$ & -3.0 & -2.4 & -17.7 & $<0.01$ \\
\hline \multirow[t]{2}{*}{ Men 85 years and over } & 1 & 1980 & 1993 & 1.5 & -0.5 & 3.6 & 1.5 & 0.10 \\
\hline & 2 & 1993 & 2015 & $-2.8^{*}$ & -3.5 & -2.2 & -9.1 & $<0.01$ \\
\hline \multirow[t]{3}{*}{ Women $65-74$ years } & 1 & 1980 & 1985 & 1.4 & -2.7 & 5.7 & 0.7 & 0.50 \\
\hline & 2 & 1985 & 2006 & $-4.0^{*}$ & -4.5 & -3.4 & -14.6 & $<0.01$ \\
\hline & 3 & 2006 & 2015 & -0.7 & -2.9 & 1.6 & -0.6 & 0.50 \\
\hline \multirow[t]{2}{*}{ Women $75-84$ years } & 1 & 1980 & 1985 & 6 & -0.6 & 13 & 1.8 & 0.10 \\
\hline & 2 & 1985 & 2015 & $-3.8^{*}$ & -4.2 & -3.4 & -18.2 & $<0.01$ \\
\hline \multirow[t]{2}{*}{ Women 85 years and over } & 1 & 1980 & 1994 & -0.1 & -2.5 & 2.3 & -0.1 & 0.90 \\
\hline & 2 & 1994 & 2015 & $-4.8^{*}$ & -5.8 & -3.7 & -9.1 & $<0.01$ \\
\hline
\end{tabular}

Annual Percentage Changes (ACP) and corresponding 95\% confidence intervals (95\% CI), ' $t$ ' test and probability levels. Men and women aged 65-74 years, 75-84 years and 85 years and over. Italy, 1980-2015

significant declines between 1985 and 2006 in the age group 65-74, and in more recent years for the older groups of age (Table 2). The APCs were the highest in old-olds in both sexes ( 2.8 males; -4.8 females).

Figure 5 illustrates the differences in rates and numbers of suicide deaths in 5-year age groups at the beginning and the end of the observations period. Suicide rates have halved while the number of deaths has remained quite similar, with bigger reductions in rates (and number of suicide cases) in women compared to men. The same figure also shows that while in 1980 the biggest number of suicide deaths concentrated in the age band 65-69 in both sexes, in 2015 biggest numbers happen to be in the age group 50-54, both in men and women. However, although the numbers peak at younger ages, particularly by 2015 , the rates continue to be clearer highest in late life for men and not much lower for women than that in the 50-54-year-of-age group (Fig. 5).

A general decline has been witnessed in all the four main geographical regions of the country (north-west, north-east, centre, and south with islands); however, the 

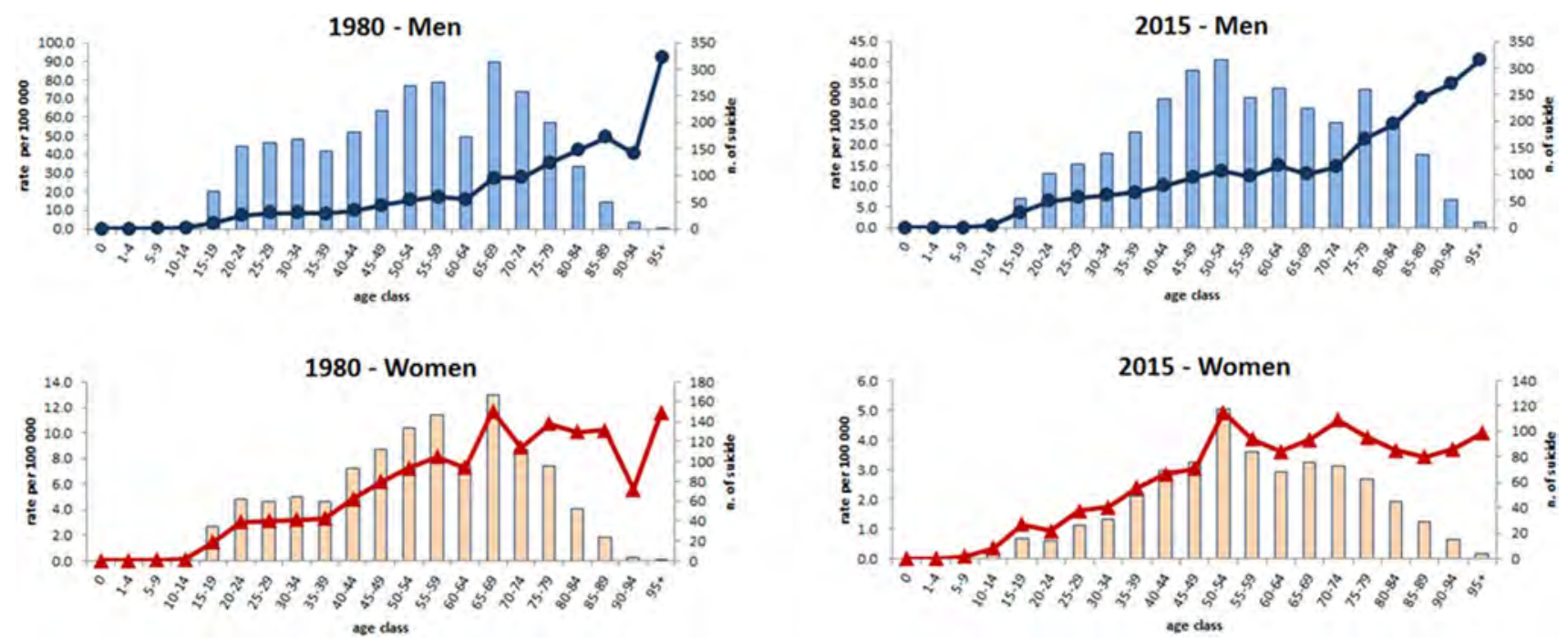

Fig. 5 Suicide deaths by age class. Age-specific rates (straight lines) per 100,000 inhabitants and number of deaths (bars). Italy, men and women. Year 1980 and year 2015

decrease was not significant in the last decade for older men of the north-western region, while it was significant in all other regions (Table 3). In women, the decrease was marked for individuals belonging to the most productive area of the country, the northeastern one. Women also showed significant declines in the south and the islands (Sicily and Sardinia).

Comparison with the age group 15-64 (Table 4) demonstrated an increasing trend, especially during the most recent decade. The only exceptions were women in the south and

Table 3 Age-adjusted suicide rates

\begin{tabular}{|c|c|c|c|c|c|c|c|c|}
\hline Cohort & Segment & Lower endpoint & Upper endpoint & APC & Lower CI & Upper CI & Test statistic $(t)$ & Prob $>|t|$ \\
\hline \multirow[t]{3}{*}{ Men 65 years and over-North West } & 1 & 1980 & 1985 & $4.9^{*}$ & 0.8 & 9.2 & 2.4 & $<0.01$ \\
\hline & 2 & 1985 & 2006 & $-3.6^{*}$ & -4.1 & -3.1 & -14.6 & $<0.01$ \\
\hline & 3 & 2006 & 2015 & -0.8 & -2.3 & 0.8 & -1.0 & 0.30 \\
\hline \multirow[t]{2}{*}{ Men 65 years and over-North East } & 1 & 1980 & 1985 & 4.6 & -3.2 & 12.9 & 1.2 & 0.20 \\
\hline & 2 & 1985 & 2015 & $-2.7 *$ & -3.2 & -2.3 & -13.0 & $<0.01$ \\
\hline \multirow[t]{2}{*}{ Men 65 years and over-Centre } & 1 & 1980 & 1985 & 4.3 & -1.8 & 10.8 & 1.4 & 0.20 \\
\hline & 2 & 1985 & 2015 & $-2.5^{*}$ & -2.9 & -2.2 & -14.9 & $<0.01$ \\
\hline \multirow{2}{*}{$\begin{array}{l}\text { Men } 65 \text { years and over-South and } \\
\text { Islands (Sicily and Sardinia) }\end{array}$} & 1 & 1980 & 1993 & 0.6 & -0.5 & 1.7 & 1.1 & 0.30 \\
\hline & 2 & 1993 & 2015 & $-2.3^{*}$ & -2.7 & -1.8 & -11.1 & $<0.01$ \\
\hline \multirow{3}{*}{$\begin{array}{l}\text { Women } 65 \text { years and over-North } \\
\text { West }\end{array}$} & 1 & 1980 & 1985 & 4.2 & -3.4 & 12.3 & 1.1 & 0.30 \\
\hline & 2 & 1985 & 2009 & $-4.2^{*}$ & -5.0 & -3.4 & -11.0 & $<0.01$ \\
\hline & 3 & 2009 & 2015 & 1.8 & -5.1 & 9.2 & 0.5 & 0.60 \\
\hline \multirow[t]{2}{*}{ Women 65 years and over-North East } & 1 & 1980 & 1987 & 2.1 & -1.2 & 5.5 & 1.3 & 0.20 \\
\hline & 2 & 1987 & 2015 & $-4.0^{*}$ & -4.4 & -3.6 & -18.1 & $<0.01$ \\
\hline \multirow[t]{3}{*}{ Women 65 years and over-Centre } & 1 & 1980 & 1994 & $-2.2 *$ & -3.6 & -0.8 & -3.2 & $<0.01$ \\
\hline & 2 & 1994 & 2007 & $-5.6^{*}$ & -7.5 & -3.7 & -5.8 & $<0.01$ \\
\hline & 3 & 2007 & 2015 & 1.3 & -2.8 & 5.5 & 0.6 & 0.50 \\
\hline \multirow{2}{*}{$\begin{array}{l}\text { Women } 65 \text { years and over-South and } \\
\text { Islands (Sicily and Sardinia) }\end{array}$} & 1 & 1980 & 1985 & 4.4 & -0.9 & 10.0 & 1.7 & 0.10 \\
\hline & 2 & 1985 & 2015 & $-2.8^{*}$ & -3.2 & -2.5 & -16.4 & $<0.01$ \\
\hline
\end{tabular}

Annual Percentage Changes (ACP) and corresponding 95\% confidence Intervals (95\% CI), test statistic $(t)$ and corresponding probability. Men and women aged 65 years and over by Geographical Region, years 1980-2015 
Table 4 Age-adjusted suicide rates

\begin{tabular}{|c|c|c|c|c|c|c|c|c|}
\hline Cohort & Segment & Lower endpoint & Upper endpoint & APC & Lower CI & Upper CI & Test statistic $(t)$ & Prob $>|t|$ \\
\hline \multirow[t]{3}{*}{ Men 15-64 years-North West } & 1 & 1980 & 1996 & 0.2 & -0.5 & 0.9 & 0.7 & 0.50 \\
\hline & 2 & 1996 & 2005 & $-3.0^{*}$ & -4.9 & -1.0 & -3.1 & $<0.01$ \\
\hline & 3 & 2005 & 2015 & 1.1 & -0.5 & 2.6 & 1.4 & 0.20 \\
\hline \multirow[t]{3}{*}{ Men 15-64 years-North East } & 1 & 1980 & 1995 & 0.4 & -0.3 & 1.2 & 1.2 & 0.20 \\
\hline & 2 & 1995 & 2006 & $-2.6^{*}$ & -3.9 & -1.2 & -3.9 & $<0.01$ \\
\hline & 3 & 2006 & 2015 & $1.7 *$ & 0.0 & 3.4 & 2.1 & $<0.01$ \\
\hline \multirow[t]{3}{*}{ Men 15-64 years-Centre } & 1 & 1980 & 1994 & 0.7 & -0.1 & 1.5 & 1.8 & 0.10 \\
\hline & 2 & 1994 & 2006 & $-1.7 *$ & -2.8 & -0.6 & -3.1 & $<0.01$ \\
\hline & 3 & 2006 & 2015 & $1.9^{*}$ & 0.3 & 3.4 & 2.5 & $<0.01$ \\
\hline \multirow{3}{*}{$\begin{array}{l}\text { Men } 15-64 \text { years-South and } \\
\text { Islands (Sicily and Sardinia) }\end{array}$} & 1 & 1980 & 1996 & $1.2^{*}$ & 0.4 & 2.0 & 3.0 & $<0.01$ \\
\hline & 2 & 1996 & 2002 & -3.1 & -7.2 & 1.1 & -1.5 & 0.10 \\
\hline & 3 & 2002 & 2015 & 0.6 & -0.4 & 1.6 & 1.2 & 0.20 \\
\hline \multirow[t]{3}{*}{ Women $15-64$ years-North West } & 1 & 1980 & 1996 & $-1.3^{*}$ & -2.0 & -0.5 & -3.6 & $<0.01$ \\
\hline & 2 & 1996 & 2002 & $-5.2 *$ & -9.5 & -0.7 & -2.3 & $<0.01$ \\
\hline & 3 & 2002 & 2015 & 0.1 & -1.1 & 1.3 & 0.1 & 0.90 \\
\hline \multirow[t]{2}{*}{ Women 15-64 years-North East } & 1 & 1980 & 2009 & $-2.0^{*}$ & -2.5 & -1.6 & -8.9 & $<0.01$ \\
\hline & 2 & 2009 & 2015 & 3.3 & -2.1 & 9.0 & 1.2 & 0.20 \\
\hline \multirow[t]{2}{*}{ Women $15-64$ years-Centre } & 1 & 1980 & 2010 & $-2.1^{*}$ & -2.5 & -1.7 & -9.6 & $<0.01$ \\
\hline & 2 & 2010 & 2015 & 4.5 & -2.8 & 12.4 & 1.2 & 0.20 \\
\hline $\begin{array}{l}\text { Women } 15-64 \text { years-South and } \\
\text { Islands (Sicily and Sardinia) }\end{array}$ & 1 & 1980 & 2015 & $-1.9^{*}$ & -2.2 & -1.7 & -16.2 & $<0.01$ \\
\hline
\end{tabular}

Annual Percentage Changes (ACP) and corresponding 95\% confidence intervals (95\% CI), test statistic $(t)$ and corresponding probability. Men and women aged 15-64 by Geographical Region, years 1980-2015

islands (Table 4). It is tempting to hypothesise that the Great Financial Crisis of 2008 could have had a role in contributing to the generalised increase in suicide rates [22, 23].

\section{Discussion}

Suicide rates in old age have markedly decreased in Italy during the study period of 1980-2015. More specifically, age-standardised suicide rates have fallen by about half in men and by more than half in women, and the decline has affected the whole peninsula. The fall in rates was more evident in the oldest age groups, being significant for old-olds $(85+)$ from mid-1990s and for middle-old from mid-1980s for both sexes. Nevertheless, despite the decline in older adults the age-specific suicide rates remained the highest for the oldest age groups in Italy, similarly to many other countries [2].

Importantly, our analyses showed that suicide trends in the youngest age group of older adults aged 65-74 years showed rather similar trends to those aged 15-64 years. Their rates showed also significant declines in 1985-2006, which was followed by plateaued trend since 2006, reflecting possibly some impact of the Great Financial Crisis of 2008, which was more strongly observed in age group 15-64 years.
This phenomenon seems to lend some support to the decision taken by Italian Geriatrics and Gerontology Society in setting up the entry point into old age at 75 years instead of at 65 years.

It seems interesting to note that while at the beginning of the observation - in 1980-the absolute number of suicide deaths concentrated in the 65-69 age group (both sexes), in 2015 the highest number of deaths was recorded in the age range between 50 and 54 for males and females. In fact, at least from a suiciodological perspective, the 65-69 years of age group does not appear to represent any longer a critical period for individuals in Italy. Marchionni, in an interview given during the national congress in Rome on November 29,2018 , claimed that '.. the sixty-five years olds of today roughly correspond to the 45 years olds of thirty years ago' [9]. For sure, life expectancy and the quality of people's lives have improved dramatically during this timeframe. As a matter of fact, in Italy poverty index has improved only for older adults, while it has deteriorated for all other age groups (OECD, 2018). However, it remains to be determined why the peaking age in terms of biggest density of cases of suicide is now between 50 and 54 years.

Despite the progressive aging of the world population and of Italy in particular (destined to become the third oldest country in terms of senior citizens after Japan and Spain by 
2050-OECD, 2018), current trends in suicide rates disprove that ageing societies have in parallel increasing suicide rates in their older members. Although poorly investigated, this fact seems to indicate the existence of some abilities of societies to react and adapt to increased numbers of senior citizens and their augmented longevity by creating acceptable living conditions. Actually, in many countries, suicide rates have fallen among older adults that very rarely have been the target of specific anti-suicide strategies, but have received the same improvements (if not less) in health and social care that were rendered available to the whole population. In addition, trends in the so-called managed care, involving reduced hospital stays and limitations in hospital resources [24] could have had an adverse effect on late life suicide rates, although this was not the case, as demonstrated by the Italian data shown in the present study.

Elderly males (especially if $80+$ years old) seem to remain the least adaptable individuals and those more vulnerable to the aggregation of risk factors of different nature (e.g., physical conditions, frailty, depression, dependency on others, etc.). Available evidence teaches us that women adjust better than men, and when situations in life become particularly critical, strategies in use to counteract them carry a more visible effect on female subjects [25]. Among other things, this may be due to women's attitude to more easily communicate their inner feelings, thus attracting and receiving emotional support [16]. However, further research would be needed to demonstrate that this attitude could explain the wider fall compared to men in suicide rates in Italy.

\section{Conclusions}

Suicide rates of senior citizens of Italy have been remarkably declining during the years 1980-2015. Decreasing trends have become evident since 1985 and have been important in size circa until 2005; since then, the slope has become less steep or stagnating. Women have recorded wider amplitude of the decline (approximately 60\%), with men recording a $50 \%$ reduction in their rates. Falls in rates have been significant for older adults aged 75 and more. All macro-geographical regions of Italy have recorded declining rates. Compared to 1980 , when most suicide cases concentrated around the age of 65-69 years, in 2015 most cases are recorded in the age group 50-54 years.

Despite the relevant and positive changes in suicide rates of older adults, these rates remain the highest compared to the rest of the Italian population. Improving health assistance and quality of life of senior citizens continue to represent an imperative for the public system.
Funding information No specific fund was requested (or obtained) for this study.

\section{Compliance with ethical standards}

Conflict of interest Authors do not declare any conflict of interest.

Ethical approval This study was based on examination of official data only. This article does not contain any studies with human participants or animals performed by any of the authors.

Informed consent No informed consent is required.

\section{References}

1. Naghavi M, on behalf of the Global Burden of Self-Harm Collaborators (2019) Global, regional, and national burden of suicide mortality 1990 to 2016: systematic analysis for the Global Burden of Disease Study 2016. BMJ 364:194. https://doi.org/10.1136/ bmj.194

2. WHO (2014) Preventing suicide: a global imperative. World Health Organization, Geneva

3. Iemmi V, Bantjes J, Coast E et al (2016) Suicide and poverty in low-income and middle-income countries: a systematic review. Lancet Psychiatry 3:774-783

4. Khazaei S, Armanmehrb V, Nematollahic S et al (2017) Suicide rate in relation to the Human Development Index and other healthrelated factors: a global ecological study from 91 countries. J Epidemiol Glob Health 7:131-134

5. Yip PSF (2008) Suicide in Asia: causes and prevention. Hong Kong University Press, Hong Kong

6. Wang CW, Chan CLW, Yip PSF (2014) Suicide rates in China from 2002 to 2011: an update. Soc Psychiatry Psychiatr Epidemiol 49:929-941. https://doi.org/10.1007/s00127-013-0789-5

7. Von Herbay A (2014) Otto von Bismarck is not the origin of old age at 65 . Gerontologist 54:5. https://doi.org/10.1093/geront/ gnt111

8. Koo YW, Kõlves K, De Leo D (2017) Suicide in older adults: differences between the young-old, middle-old, and oldest-old. Int Psychogeriatr 29:1297-1306. https://doi.org/10.1017/s1041 610217000618

9. Marchionni N (2018) Interviewed in 'Rivoluzione età, si diventa anziani a 75 anni'. [Age revolution, one becomes an elderly person at 75 years]. Il Messaggero, Rome, 30 November

10. Shah A, Zarate-Escudero S, Bhat R et al (2014) Suicide in centenarians: the international landscape. Int Psychogeriatr 26:1-6

11. Canetto SS (1995) Elderly women and suicidal behavior. In: Canetto SS, Lester D (eds) Women and suicidal behaviour. Springer Publishing Company, New York

12. De Leo D, Kõlves K (2017) Suicide at very advanced age-the extremes of the gender paradox. Crisis 38:363-366

13. De Leo D (2015) Can we rely on suicide mortality data? Crisis 36:1-3. https://doi.org/10.1027/0227-5910/a000315

14. Williams RF, Doessel DP, Sveticic J et al (2010) Accuracy of official suicide mortality data in Queensland. Aust N Z J Psychiatry 44:815-822

15. Abercrombie GC (2006) Suicide in the elderly master thesis. Washington State University, Washington DC

16. DeLeo D, Arnautovska U (2016) Prevention and treatment of suicidality in older adults. In: O'Connor R, Pirkis J (eds) International handbook of suicide prevention Research, policy and practice. Wiley Blackwell, Chichester, pp 323-345 
17. Walter SJ, Bugeja L, Spittal MJ et al (2012) Factors predicting coroners' decisions to hold discretionary inquests. Can Med Assoc J 185:522-528

18. Sassoon D (1997) Contemporary Italy: economy, society, and politics since 1945. Longman, New York

19. Buch CM, Monti P (2010) Openness and income disparities: does trade explain the 'mezzogiorno effect'? Rev World Econ 145:667-688. https://doi.org/10.1007/s10290-009-0038-x

20. De Leo D, Conforti D, Carollo G (1997) A century of suicide in Italy: a comparison between the old and the young. Suicide Life Threat Behav 27:239-249

21. Minelli G, Manno V, D'Ottavi SM et al (2010) La mortalità in Italia nell' anno. [Mortality in Italy in 2006]. Appendice B [Appendix B]. Rapporti ISTISAN.;26 Istituto Superiore di Sanità

22. Mattei G, Pistoresi B, De Vogli R (2019) Impact of the economic crises on suicide in Italy: the moderating role of active labor market programs. Soc Psychiatry Psychiatr Epidemiol 54:201-208. https://doi.org/10.1007/s00127-018-1625-8
23. Pompili M, Vichi M, Innamorati M et al (2014) Suicide in Italy during a time of economic recession: some recent data related to age and gender based on a nationwide register study. Health Soc Care Community 22:361-367. https://doi.org/10.1111/hsc.12086

24. De Falco R (2018) Death by a million cuts: what future for the right to health in Italy?. Center for Economic and Social Rights, New York. http://www.cesr.org/death-million-cuts-what-futur e-right-health-italy

25. De Leo D, Dello Buono M, Dwyer J (2002) Suicide among the elderly: the long-term impact of a telephone support and assessment intervention in northern Italy. Br J Psychiatry 181:226-229

Publisher's Note Springer Nature remains neutral with regard to jurisdictional claims in published maps and institutional affiliations. 